\title{
Molecular characterization of a re-emergent Brugia malayi parasite in Sri Lanka, suggestive of a novel strain with close nucleotide homology to Brugia pahangi
}

Chandana Harendra Mallawarachchi ( $\square$ harendra9791@gmail.com )

Medical Research Institute https://orcid.org/0000-0003-4238-8931

Nilmini T. G. A. N Chandrasena

University of Kelaniya

Ranjan Premarathna

University of Kelaniya

S.M.N.S.M. Maleesha Mallawarachchi

Ministry of Health, Sri Lanka

Nilmini Y. I. S. Gunawardane

University of Kelaniya

Ranil S Dasanayake

University of Colombo

Nilanthi R de Silva

University of Kelaniya

Research Article

Keywords: Brugia malayi, Brugia pahangi, Human, Cats, Dogs, Hybrid, Novel strain

Posted Date: September 9th, 2020

DOl: https://doi.org/10.21203/rs.3.rs-69977/v1

License: (c) (1) This work is licensed under a Creative Commons Attribution 4.0 International License.

Read Full License 


\section{Abstract}

Background Brugian filariasis has re-emerged in Sri Lanka after four decades of quiescence. As microscopy alone was insufficient for ascertaining the species identity of the re-emerged sub-periodic Brugia spp. parasite, molecular speciation was performed. The transmission dynamics of the parasite was studied by entomological procedures.

Methods Human blood samples positive for Brugia spp. microfilariae (MF) ( $\mathrm{n}=8$ ) were collected and DNA extracted using ReliaPrep ${ }^{\mathrm{TM}}$ Blood DNA Miniprep System (modified). Polymerase chain reaction (PCR) was performed with pan-filarial primers specific for the internal transcribed spacer region 2 (ITS2) of the ribosomal DNA (rDNA) of MF.

Results Of those tested, seven (87.5\%) yielded a band at 615bp establishing the species identity of the reemerged filarial parasite as B. malayi. Comparison of the ITS2 region gene sequences of B. malayi MF isolated from humans $(n=2)$, dogs $(n=3)$ and cats $(n=6)$ with GenBank sequences revealed a higher sequence homology with B. pahangi than B. malayi, but phylogeny was closer to B. malayi. A total of 82 mosquitoes of genus Mansonia comprising of M. annulifera (65), M. uniformis (14) and M. indiana (3) were collected by cattle-baited traps. Mosquito dissections identified 17 infected mosquitoes: one $M$. uniformis (7.14\%) and $16 \mathrm{M}$. annulifera (24.6\%). The DNA extracts of all infected Mansonia mosquitoes elicited the $615 \mathrm{bp}$ band on pan-filarial primer specific PCR.

Conclusions The re-emergent $B$. malayi is a genetic variant or a novel species closely related to $B$. malayi and $B$. pahangi. Mansonia spp. mosquitoes were vectors of this zoonotic variant $B$. malayi circulating among cats, dogs and humans in Sri Lanka.

\section{Background}

Lymphatic filariasis (LF), is a neglected tropical disease estimated to have affected 40 million people worldwide, with an at risk population of 893 million people residing in 49 endemic countries [1]. Although infection is not fatal, it is a leading cause of permanent disability and was targeted for elimination as a public health problem by 2020 [1].

Three species of filarial worms, namely Wuchereria bancrofti, Brugia malayi (nocturnally periodic strain) and Brugia timori are known to cause classical lymphatic filariasis in humans. Of the three human filarial parasites, $W$. bancrofti is the most prevalent, causing $90 \%$ of infections worldwide, while the rest are attributed to B. malayi (prevalent in Southeast Asia and in South-western parts of India) and to a lesser extent $B$. timori (limited to the islands of Timor-Leste in eastern Indonesia) [1]. A zoonotic strain of $B$. malayi (sub-periodic strain), which is a natural parasite of a variety of wild and domestic animals (cats, dogs, monkeys, slow-lorises) has been documented to cause accidental zoonotic infections in humans [2] [3] [4] [5]. Serological and molecular evidence of human infections by another zoonotic filarial worm, $B$. pahangi (a natural parasite of felines) has been reported from Kuala Lumpur, with clinical manifestations consistent with lymphatic filariasis [6]. These zoonotic filariae (sub-periodic B. malayi and B. pahangi) 
also contribute to the human disease burden especially in the Northeastern United States, South America and Southeast Asian region [2] [3] [7].

Both W. bancrofti and B. malayi (nocturnally periodic strain) were prevalent in Sri Lanka in the past [8]. Vector control activities focussed on clearance of aquatic vegetation (a requirement for breeding of Mansonia spp. mosquitoes) resulted in clearance of B. malayi infections from the country in late nineteen sixties [8]. Subsequently five rounds of single annual mass drug administration (MDA) was implemented from 2002-2006 in the three provinces (Western, Northwestern and Southern) endemic for bancroftian filariasis using diethylcarbamazine citrate $(300 \mathrm{mg}$ ) combined with albendazole (400 mg). In 2016 Sri Lanka was categorized as a country that had eliminated LF as a public health problem, following fulfilment of critical criteria stipulated by World Health Organization (WHO) for verification of elimination [9]. However, surveillance activities during the phases of post-MDA and post-elimination revealed the sporadic occurrence of brugian filariasis in all three LF endemic provinces [10] [11] [12] [18]. Periodicity studies revealed that the re-emergent Brugia species microfilaria (MF) exhibited nocturnal sub-periodicity, implying a strain of different origin [10]. Zoonotic surveillance in areas affected by human brugian filariasis has revealed a high prevalence of $B$. malayi MF among dogs and cats [13]. The existence of another zoonotic filarial species, Brugia ceylonensis among local canines has also been documented in the past [14].

Exact speciation of the re-emerged Brugia parasite was important as zoonotic B. malayi, B. pahangi and B. ceylonensis have all been implicated in accidental human infections [15] [4] [5] [6]. The morphological similarity of the MF of Brugia spp. necessitated a molecular based approach (PCR and sequencing) for species identification [15].

Studies on the genetic variability of $B$. malayi indicate that parasite isolates from different regions diverged significantly [16]. Gene sequences of zoonotic Brugia species are sparse in major data bases and with increasing case numbers there will be an increased need for genomic repositories [17]. Such information may support the genus or species clarifications based on consensus gene targets. Thus, sequencing of the Brugia spp. MF that were isolated from humans and animals of Sri Lanka were carried out to construct the phylogeny and assess their relationship to other Brugia species.

Knowledge of the transmission dynamics of the newly emerged parasite is important for control. The vector preferences of the re-emerged parasite may differ from the nocturnal periodic strain of $B$. malayi documented in the past; thus, entomological investigations were performed for clarification of the vector species.

Against this background of events, a comprehensive analysis of the re-emerged Brugia spp. parasite of Sri Lanka, as to its species identity, the phylogeny and genetic relatedness to other Brugia species and its vector preferences were studied using conventional parasitological and molecular methods.

\section{Methods}




\section{Human sample collection and DNA extraction}

Human blood samples positive for Brugia sp. MF by thick night blood smears (NBS) were collected from four districts belonging to the three endemic provinces, (Gampaha and Kalutara from the Western province $n=5$; Puttalam from the North-western province $n=1$ and Galle from the Southern province $n=$ 1) and from a case detected from a non-endemic district in the North Central province (Anuradhapura). Blood samples positive for Brugia antibodies by the Brugia rapid test were also included in the molecular analysis. The samples were stored at $-20^{\circ} \mathrm{C}$ in EDTA prior to DNA extraction. The MF in blood was concentrated by Nuclepore ${ }^{\circledR}$ membrane filtration and the filter membranes with trapped MF were used for DNA extraction. The DNA was extracted using the ReliaPrep ${ }^{\mathrm{TM}}$ Blood DNA Miniprep System (Catalogue number A5082) according to the manufacturer's instructions [18] with some modifications.

Briefly, a volume of $180 \mu \mathrm{l}$ of PBS was added to polycarbonate membranes with MF and incubated for 45 minutes while shaking ( $300 \mathrm{rpm}$ ). A volume of $20 \mu$ Proteinase $\mathrm{K}$ and $200 \mu \mathrm{l}$ cell lysis buffer solution was then added to the content and incubated at $56^{\circ} \mathrm{C}$ for 10 minutes and to which $250 \mu$ l of binding buffer were added. The content was then transferred to ReliaPrep ${ }^{\mathrm{TM}}$ binding columns and centrifuged at $5000 \mathrm{Xg}$. The binding columns were transferred to fresh collection tubes and $500 \mu \mathrm{l}$ of column wash solution was added and centrifuged for three minutes at $5000 \mathrm{Xg}$ and this was then repeated twice. The binding columns were finally eluted with $50 \mu$ l Nuclease-Free water. The DNA concentrations was measured by fluorometry according to the instructions (Manual \#TM396: www.promega.com/protocols/) and stored at $-20^{\circ} \mathrm{C}$ until used.

\section{DNA amplification}

The procedure stated by Rishniw et al., 2006 was used with some modifications using Promega reagents [24]. The pan-filarial primers (DIDR-F1 5'-AGT GCG AAT TGC AGA CGC ATT GAG-3' and DIDR-R1 5'-AGC GGG TAA TCA CGA CTG AGT TGA-3') that spanned the ITS2 of the rDNA designed by Rishniw et al., 2006 was employed to amplify the target DNA region [24]. Known positive and negative controls were included in each PCR reaction. The PCR procedure consisted of an initial denaturing step at $94^{\circ} \mathrm{C}$ for 2 min and 32 cycles of denaturing $\left(30 \mathrm{~s}\right.$ at $\left.94^{\circ} \mathrm{C}\right)$, annealing $\left(30 \mathrm{~s}\right.$ at $\left.58^{\circ} \mathrm{C}\right)$ and extension $\left(30 \mathrm{~s}\right.$ at $\left.72{ }^{\circ} \mathrm{C}\right)$ and final extension $\left(7 \mathrm{~min}\right.$ at $\left.72^{\circ} \mathrm{C}\right)$ in an Eppendorf Mastercycler thermal cycler.

Discrimination of the six species was based on the size of the amplified PCR products. DIDR-F1 and DIDR-R1 primers amplified 484 bp, 542 bp, 578 bp, 584 bp, 615 bp and 664 bp products from Dirofilaria repens, Dirofilaria immitis, Acanthocheilonema reconditum, Acanthocheilonema dracunculoides, $B$. malayi, and B. pahangi respectively [19].

\section{Canine and feline sample processing}

The zoonotic surveillance for filarial parasites were done at three locations in the districts of Gampaha (Weliweriya and Wattala) and Puttalam (Madampe) of Western and Northwestern provinces respectively and molecular speciation of the zoonotic Brugia parasite was performed by PCR using panfilarial primers specific for ITS2 region and species confirmed as B. malayi as detailed previously [13]. 


\section{Mosquito vector analysis \\ Sample collection, DNA extraction and amplification}

The mosquito surveillance was carried in the district of Gampaha in the same areas where zoonotic surveillance was done, using one cattle-baited trap in each location. Mosquitoes of Mansonia sp. were identified using morphological keys. Heads and thoraces of all Mansonia sp. mosquitoes were dissected to identify filarial larvae.

DNA of filarial larvae was extracted using the MightyPrep reagent (Takara Bio Inc, Japan) according to manufacturer's guide with some modifications as follows: the mosquito heads and thoraces that were positive for filarial larvae were crushed and mounted temporarily on glass slides and flushed with $200 \mu \mathrm{L}$ of MightlyPrep reagent into a microcentrifuge tube. The lysate was homogenized by hard vortexing for 10 seconds. New pipette tips were used each time to prevent cross contamination of samples. The lysates were incubated at $95^{\circ} \mathrm{C}$ for 10 minutes. Subsequently the sample lysates were allowed to cool down to room temperature. The cooled lysates were hard-vortexed for another 10 seconds. Finally, the samples were centrifuged at $12,000 \mathrm{rpm}$ for 10 minutes and stored at $-20^{\circ} \mathrm{C}$ until used for PCR. DNA amplification was done using the same set of primers and procedure used for human and animals' samples.

\section{DNA sequencing}

The Sanger method[20] was applied in cycle sequencing of amplified PCR products (ITS2 region of rDNA) of MF in blood samples of humans $(n=2)$ \{Pubudugama (1) and Weliweriya (1)\}, canines $(n=3)$ (Pubudugama) and felines $(n=6)$ \{Pubudugama (2), Madampe (4)\}. Sample selection was based on the concentration of the DNA extracts.

\section{Homology comparison}

The DNA sequence homology was analysed using BLASTN. Mega 07 (https://rom yhe studywww.ncbi.nlm.nih.gov/pubmed/27004904) tool and the analysed data was used to generate the phylogenetic tree. Based on NCBI (https://www.ncbi.nlm.nih.gov/) blast, closely related sequences to Brugia sp. genes were retrieved.

\section{Results}

\section{PCR}

Seven of the eight human blood samples positive for Brugia sp. MF by NBS that were tested by PCR, produced a band of 615 bp specific for B. malayi (Fig. 1).

Figure 01. Gel electrophoresis of the PCR products of human samples; The gel image shows the results of the PCR amplification of samples 1 to 7 using Pan-filarial primers (Lanes 1 to 5 - human samples, Lane 6positive control, Lane 7- negative control and Lane L- 50 bp DNA marker.) 
The sample that failed to elicit a PCR band had very low microfilaraemia (1MF/slide). All human blood samples that were only positive for anti-Brugia antibodies by BRT $(n=9)$ failed to elicit a PCR band. The zoonotic samples also elicited bands of 615 bp specific for B. malayi (Fig. 2).

Figure 02. Gel electrophoresis of Pan-filarial primer specific PCR amplicons of human, canine and feline samples from the zoonotic study area Pubudugama, The gel image shows the results of the Pan-filarial primers specific PCR amplification of samples 1 to 9 (Lanes 1- human sample, Lane 2 to 4 - Dog samples, Lane 5 to 7- cat samples Lane 8- positive control, Lane 9- negative control and Lane L- 50 bp DNA marker.)

A total of 82 Mansonia sp. mosquitoes were identified in the cattle-baited-trap collection, namely, $M$. annulifera (65), M. uniformis (14) and $M$. indiana (3).

Filarial larval stages were detected in 20.73\% (17/82) of the dissected Mansonia mosquitoes. Of them, $7.14 \%(1 / 14)$ and $24.6 \%(16 / 65)$ were $M$. uniformis and $M$. annulifera respectively. The DNA extracts of all infected Mansonia mosquitoes elicited the $615 \mathrm{bp}$ band of $B$. malayi when analyzed by pan-filarial primers specific PCR.

\section{Phylogenetic analysis}

A homology search carried out on GenBank using the BLASTN of NCBI and the amplified ITS2 sequences of the B. malayi MF of humans, dogs' and cats' in this study showed the sequences to have higher homology with B. pahangi than B. malayi (Fig. 3).

Phylogenetic analyses of the sequenced ITS2 gene of $B$. malayi MF from human, canine and feline blood samples clustered between B. pahangi and B. malayi. All were in a monophyletic group originating from the same ancestor except for one sample (No 5), which fell to a more distant location. The sequences obtained in the current study formed a separate cluster, with three sub-clusters within it (Fig. 3). Phylogenetic tree based on the nucleotide sequences of the ITS2 gene.

Figure 3.Phylogenetic tree constructed from partial rDNA sequencing, (ITS2 region); The phylogenetic tree was constructed using the aligned sequences with Mega 07 tool. The lengths of the horizontal lines are proportional to the minimum number of nucleotide differences required to join nodes. Vertical lines are for spacing branches and labels. Numerical numbers in the nodes are bootstrap confidence intervals which were calculated by 1000 heuristic search replicates. The reference strain was given accession numbers (bold and Italic). \{Cluster A - 4 (Dog - Pubudugama) and 26 (Human - Pubudugama); Cluster B - 8, 6 (CatPubudugama), 14, 19 (Cat - Madampe), 27 (Human - Weliweriya); Cluster C - 17 (Cat- Madampe), 3 (Dog - Pubudugama) and 15 (Cat- Madampe).

\section{Discussion}

Molecular characterization confirmed that the re-emerged sub-periodic Brugia parasite was the same as that circulating among dogs and cats in the region. Sequencing the ITS2 region of the rDNA of both 
human and zoonotic parasites indicated that the infecting B. malayi had a higher sequence homology to B. pahangithan B. malayi. However, phylogeny reconstruction based on phylogenetic tree indicated that the phylogeny of the parasite was closer to B. malayi.

The possibilities for this ambiguous outcome are two-fold. The first is that the re-emergent species is a naturally occurring hybrid species of $B$. malayi and B. pahangi. The second possibility is that it is a hitherto undetected genetic variant or a novel species of $B$. malayi. Although interspecies hybrization of Brugia species has been reported under experimental conditions with production of viable offspring (microfilariae) [21], it has not been reported to occur under natural conditions. Under experimental hybridization only the female progeny was fertile, requiring mating with parental stock for maintenance of the hybrid strain [21]. Analysis of zoonotic blood specimens by PCR failed to detect any other brugian filarial parasites other than B. malayi. Thus, the requirement for mating between hybrid females and males of parental stock to produce viable MF cannot be fulfilled. This raises the likelihood that the reemergent $B$. malayi is a novel strain or genetic variant rather than an evolutionary mature hybrid of $B$. pahangi and B. malayi.

The presence of a novel zoonotic Brugia species closely related to B. malayi and B. pahangi has been previously queried on molecular characterization of the rDNA sequences of a filarial nematode and comparison with known gene sequences in the GeneBank [22]. These filarial nematodes were isolated from the inguinal lymph nodes of a patient based in the city of New York with an extensive travel history to Central America and the Caribbean[22].

A canine survey in Kerala, had reported the presence of $B$. malayi like MF that had elicited a histochemical staining pattern consistent with that of $B$. malayi. The Hha1 primer PCR product of this $B$. malayi like parasites were cloned and sequenced ( 2 clones, Accession numbers JN 601136 and JN 601137) and the phylogeny revealed that the $B$. malayilike parasite was genetically closer to $B$. pahangi suggesting the existence of a novel species / genetic variant closely related to $B$. malayi and $B$. pahangi in the natural environment [23].

The possibility of this variant strain of $B$. malayi being the species documented as $B$. ceylonensis requires due consideration. The adult filarial nematodes of $B$. ceylonensis was first described in 1962 in the lymphatic glands of dogs from Sri Lanka. It was documented as a novel species closely related to $B$. patei based on morphological characteristics [24]. The sheathed MF of $B$. ceylonensis had a close resemblance to MF of B. malayi (length of cephalic space) [24].

Most zoonotic brugian infections are associated with unapparent or mild symptoms and serologic testing for Bm14 lgG4 is not reliable, thus the recorded cases may be an underestimate of the true burden of infection. This variant $B$. malayi appears to have a limited capacity to infect humans as case numbers were relatively low compared to the heavy zoonotic reservoirs of infection in Sri Lanka [13]. This could be attributed to low transmissibility owing to vector characteristics (low affinity of Mansonia sp. mosquitoes for human blood) or the enhanced immune response generated by a poorly adapted zoonotic parasite conferring natural resistance to infection [10]. The rising number of cases in the recent past may be 
indicative of the parasite's potential to evolve and adapt to humans or may be a reflection of the research interest generated by the PELF.

Sentinel surveillance of animals and xenomonitoring may serve in defining populations at risk of infection. Vector identification is important not only for implementing the appropriate vector control measures but also for mapping the distribution of infection. $M$. annulifera and $M$. uniformis are zooanthropophagic mosquito species in Sri Lanka that were implicated in the transmission of periodic $B$. malayi in the past [25] [26]. This study confirmed their capability of transmitting the variant B. malayi (subperiodic) in Sri Lanka.

The ITS regions 1 and 2 have been used by many investigators for studies on phylogenetic reconstruction, genetic variability and divergence of closely related taxa of a wide range of organisms [27] [28] [29]. The molecular characterization of the MF of this variant $B$. malayi isolated from humans was limited to two samples and analysis was focussed only on the ITS2 region of the rDNA are some of the limitations of this study. A more comprehensive genome wide analysis of rDNA as well as mitochondrial DNA of MF and adult stages; and chromosome number, gonad organization of this variant B. malayi may be required for clarification of the taxonomy of the parasite. Further studies on B. malayi parasites isolated from humans and animals from different geographical locations in the country as well as comprehensive entomological surveys which cover a wide array of mosquito species are indicated in order to characterise the novel variant zoonotic B. malayi.

\section{Conclusion}

The re-emerged $B$. malayi parasite in Sri Lanka is a novel genetic variant which has a closer genetic homology to $B$. pahangithan B. malayi. Domestic canines and felines were identified as the zoonotic reservoirs and Mansonia sp. mosquitoes ( $M$. annulifera and $M$. uniformis) were implicated as vectors. This re-emerged parasite could well pose a threat to the LF elimination status of the country because vectors and infectious zoonotic reservoirs are present in abundance. The application of molecular identification techniques will be invaluable for clarification of taxonomy, epidemiology and ecology of this novel genetic variant $B$. malayi.

\section{Declarations}

\section{Ethics approval and consent to participate}

Ethical clearance for the study was obtained from the Ethics Review Committees of the Faculty of Medicine University of Kelaniya (P/108/09/2016) and the Medical Research Institute (40/2016). Informed written consent was obtained from all adult participants and one of the parent or guardian for less than 18 years old participants. In additional to the consent, written assent was obtained from participants between 7 and 18 years of age. Informed written consent was obtained from owner of the cats and dogs.

\section{Consent for publication}


Not applicable

\section{Availability of data and material}

The datasets analysed during the current study are available from the corresponding author on reasonable request.

\section{Competing interests}

The authors declare that they have no competing interests.

Funding: Financial assistance by University of Kelaniya, Sri Lanka (Strengthening Research 2016, grant No. RP/03/SR/04/06/01/2016) and Medical Research Institute (Project No. 40/2016).

\section{Authors contributions}

$\mathrm{CH}$ and TGAN took part in the design and conception of the study. $\mathrm{CH}$ involved in data collection basic molecular works. NG and RD analysed the molecular results. $\mathrm{CH}$, SMNSM involved in drafting the manuscript. TGAN, RP and NG revised manuscript critically for important intellectual content. NR gave overall supervision and final approval of the version to be published. All authors read and approved the final manuscript.

\section{Acknowledgements}

The authors wish to thank Mr Tharaka Wijerathna, Gayan Parakrama, Lalinka Herath for the support provided to improve the quality of images.

\section{References}

1. World Health Organization. Lymphatic filariasis [Internet]. Key facts. 2020. Available from: https://www.who.int/en/news-room/fact-sheets/detail/lymphatic-filariasis

2. Orihel TC, Eberhard ML. Zoonotic filariasis. Clin Microbiol Rev. 1998;11:366-81.

3. Beaver PC, Orihel TC. Human Infection with Filariae of Animals in the United States *. The American Journal of Tropical Medicine and Hygiene. 1965;14:1010-29.

4. Kanjanopas K, Choochote W, Jitpakdi A, Suvannadabba S, Loymak S, Chungpivat S, et al. Brugia malayi in a naturally infected cat from Narathiwat Province, southern Thailand. Southeast Asian $\mathrm{J}$ Trop Med Public Health. 2001;32:585-7.

5. Chansiri K, Tejangkura T, Kwaosak P, Sarataphan N, Phantana S, Sukhumsirichart W. PCR based method for identification of zoonostic Brugia malayi microfilariae in domestic cats. Mol Cell Probes. 2002;16:129-35.

6. Tan LH, Fong MY, Mahmud R, Muslim A, Lau YL, Kamarulzaman A. Zoonotic Brugia pahangi filariasis in a suburbia of Kuala Lumpur City, Malaysia. Parasitol Int. 2011;60:111-3. 
7. Eberhard ML, DeMeester LJ, Martin BW, Lammie PJ. Zoonotic Brugia Infection in Western Michigan: The American Journal of Surgical Pathology. 1993;17:1058-61.

8. Schweinfurth U. Filarial diseases in Ceylon: a geographic and historical analysis. Ecol Dis. 1983;2:309-19.

9. WHO. WHO officially declares Sri Lanka filariasis free [Internet]. 2016. Available from: http://www.searo.who.int/srilanka/documents/WHO_officially_declares_Sri_Lanka_filariasis_free/en/

10. Mallawarachchi $\mathrm{CH}$, Nilmini Chandrasena TGA, Premaratna R, Mallawarachchi SMNSM, de Silva NR. Human infection with sub-periodic Brugia spp. in Gampaha District, Sri Lanka: a threat to filariasis elimination status? Parasites \& Vectors [Internet]. 2018 [cited 2020 Jun 24];11. Available from: https://parasitesandvectors.biomedcentral.com/articles/10.1186/s13071-018-2649-3

11. Chandrasena NTGA, Premaratna R, Samarasekera DS, de Silva NR. Surveillance for transmission of lymphatic filariasis in Colombo and Gampaha districts of Sri Lanka following mass drug administration: Table 1. Transactions of The Royal Society of Tropical Medicine and Hygiene. 2016;110:620-2.

12. Fischer $P$, Bonow I, Supali T, Rückert $P$, Rahmah N. Detection of filaria-specific IgG4 antibodies and filarial DNA, for the screening of blood spots for Brugia timori. Ann Trop Med Parasitol. 2005;99:5360.

13. Mallawarachchi $\mathrm{CH}$, Chandrasena NTGA, Wickramasinghe S, Premaratna R, Gunawardane NYIS, Mallawarachchi NSMSM, et al. A preliminary survey of filarial parasites in dogs and cats in Sri Lanka. Devleesschauwer B, editor. PLOS ONE. 2018;13:e0206633.

14. Rajapakshe R, Perera W, Ihalamulla F, Weerasena K, Jayasinghe S, Sajeewani H, et al. Study of dirofilariasis in a selected area in the Western Province. Ceylon Medical Journal. 2010;50:58.

15. Palmieri JR, Ratiwayanto S, Masbar S, Tirtokusumo S, Rusch J, Marwoto HA. Evidence of possible natural infections of man with Brugia pahangi in South Kalimantan (Borneo), Indonesia. Trop Geogr Med. 1985;37:239-44.

16. Fong M-Y, Noordin R, Lau Y-L, Cheong F-W, Yunus MH, Idris ZM. Comparative analysis of ITS1 nucleotide sequence reveals distinct genetic difference between Brugia malayi from Northeast Borneo and Thailand. Parasitology. 2013;140:39-45.

17. Paniz Mondolfi A, Sordillo E. Invited Editorial: Zoonotic Lymphatic Filariasis in the Americas: Trends in Epidemiology, Diagnosis and Treatment, with Special Emphasis on Brugian Filariasis. Recent Patents on Anti-Infective Drug Discovery. 2015;9:161-3.

18. ReliaPrep ${ }^{T M}$ Blood gDNA Miniprep System; Technical Manual [Internet]. Promega Corporation; 2012. Available from: https://www.promega.com/-/media/files/resources/protocols/technicalmanuals/101/reliaprep-blood-gdna-miniprep-system-protocol.pdf

19. Rishniw M, Barr SC, Simpson KW, Frongillo MF, Franz M, Dominguez Alpizar JL. Discrimination between six species of canine microfilariae by a single polymerase chain reaction. Vet Parasitol. 2006;135:303-14. 
20. Sanger F, Nicklen S, Coulson AR. DNA sequencing with chain-terminating inhibitors. Proc Natl Acad Sci USA. 1977;74:5463-7.

21. Suswillo RR, Denham DA, McGreevy PB, Nelson GS. Hybridization between Brugia patei, B. pahangi and sub-periodic B. malayi. Parasitology. 1978;77:153-60.

22. Paniz-Mondolfi AE, Gárate T, Stavropoulos C, Fan W, González LM, Eberhard M, et al. Zoonotic Filariasis Caused by Novel Brugia sp. Nematode, United States, 2011. Emerging Infectious Diseases [Internet]. 2014 [cited 2020 Jun 25];20. Available from: http://wwwnc.cdc.gov/eid/article/20/7/131654_article.htm

23. Ravindran R, Varghese S, Nair SN, Balan VM, Lakshmanan B, Ashruf RM, et al. Canine Filarial Infections in a Human Brugia malayi Endemic Area of India. BioMed Research International. 2014;2014:1-9.

24. Jayewardene LG. On Two Filarial Parasites from Dogs in Ceylon, Brugia ceylonensis n.sp. and Dipetalonema sp.inq. Journal of Helminthology. 1962;36:269.

25. Dissanaike AS, Abeyewickreme W, Wijesundera MD, Weerasooriya MV, Ismail MM. Human dirofilariasis caused by Dirofilaria (Nochtiella) repens in Sri Lanka. Parassitologia. 1997;39:375-82.

26. McNulty SN, Mitreva M, Weil GJ, Fischer PU. Inter and intra-specific diversity of parasites that cause lymphatic filariasis. Infection, Genetics and Evolution. 2013;14:137-46.

27. Rojas M de, M. M, J. U, C. C, M. N, D. G. Phylogenetic relationships in rhinonyssid mites (Acari: Rhinonyssidae) based on ribosomal DNA sequences: insights for the discrimination of closely related species. Parasitology Research. 2002;88:675-81.

28. Morales-Hojas R, Cheke RA, Post RJ. A preliminary analysis of the population genetics and molecular phylogenetics of Onchocerca volvulus (Nematoda: Filarioidea) using nuclear ribosomal second internal transcribed spacer sequences. Memórias do Instituto Oswaldo Cruz. 2007;102:879-82.

29. Subbotin S, Maafi ZT, Moens M. Molecular identification of cyst-forming nematodes (Heteroderidae) from Iran and a phylogeny based on ITS-rDNA sequences. Nematology. 2003;5:99-111.

\section{Figures}




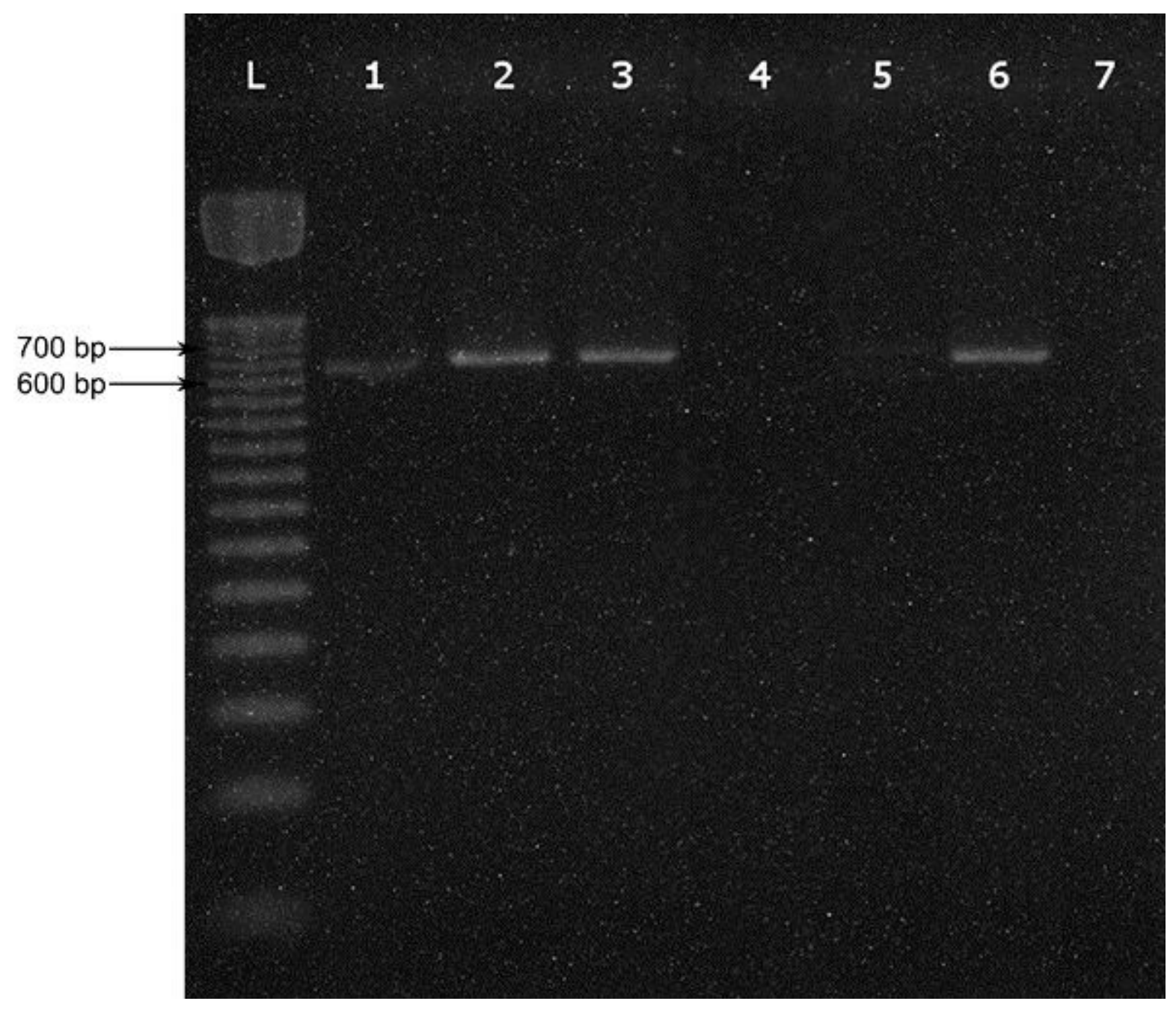

\section{Figure 1}

Gel electrophoresis of the PCR products of human samples; The gel image shows the results of the PCR amplification of samples 1 to 7 using Pan-filarial primers (Lanes 1 to 5-human samples, Lane 6-positive control, Lane 7- negative control and Lane L-50bp DNA marker.) 


$\begin{array}{llllllllll}\mathrm{L} & 1 & 2 & 3 & 4 & 5 & 6 & 7 & 8 & 9\end{array}$

\section{$700 \mathrm{bp}$} $600 \mathrm{bp}$

\section{Figure 2}

Gel electrophoresis of Pan-filarial primer specific PCR amplicons of human, canine and feline samples from the zoonotic study area Pubudugama, The gel image shows the results of the Pan-filarial primers specific PCR amplification of samples 1 to 9 (Lanes 1- human sample, Lane 2 to 4 - Dog samples, Lane 5 to 7- cat samples Lane 8- positive control, Lane 9- negative control and Lane L-50bp DNA marker.) 


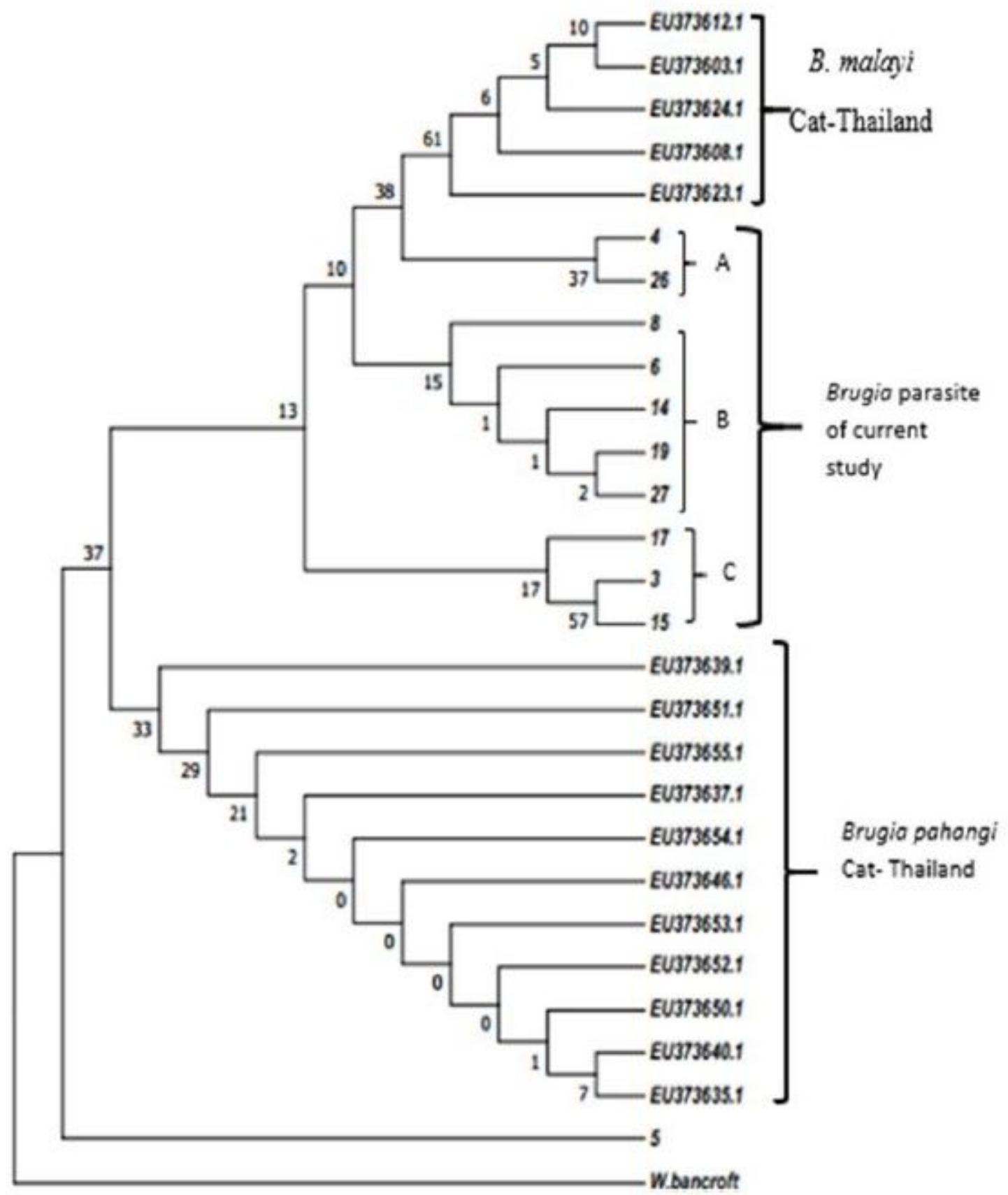

Figure 3

Phylogenetic tree constructed from partial rDNA sequencing, (ITS2 region); The phylogenetic tree was constructed using the aligned sequences with Mega 07 tool. The lengths of the horizontal lines are proportional to the minimum number of nucleotide differences required to join nodes. Vertical lines are for spacing branches and labels. Numerical numbers in the nodes are bootstrap confidence intervals which were calculated by 1000 heuristic search replicates. The reference strain was given accession numbers (bold and Italic). \{Cluster A - 4 (Dog - Pubudugama) and 26 (Human - Pubudugama); Cluster B - 8, 6 (Cat- 
Pubudugama), 14, 19 (Cat - Madampe), 27 (Human - Weliweriya); Cluster C - 17 (Cat- Madampe), 3 (Dog - Pubudugama) and 15 (Cat- Madampe).

\section{Supplementary Files}

This is a list of supplementary files associated with this preprint. Click to download.

- Sequencealingment.docx

- Grapicalabstract.pdf 